\title{
O DESAFIO DA GOVERNANÇA COLABORATIVA EM UM CONTEXTO DE COOPETIÇÃO: ANÁLISE DO P̧ROCESSO DE MUDANÇA ESTRATÉGICA DE UM ARRANJO PRODUTIVO LOCAL - APL
}

\author{
The Challenge of Collaborative Governance in a Cooperation Context: Analysis of Strategic \\ Change Process of a Local Productive Arrangement - LPA
}

\begin{abstract}
RESUMO
O contexto deste estudo é a interdependência de fatores locais e específicos das organizações no sentido de produzir vetores competitivos sustentáveis. Disto emergem um conjunto de iniciativas e relações no sentido de organizar e produzir um alinhamento mínimo entre um conjunto de empresas do Arranjo Produtivo Local Pós-Colheita Panambi-Condor/RS, objeto desta investigação. A partir da indagação sobre o modo como foi operada a governança colaborativa neste ambiente, o estudo analisou o modo como se estabeleceram as relações entre os diversos atores do APL e como elas interferiram no vigor do sistema como um todo. Baseado na percepção dos integrantes do comitê gestor e gestores das empresas integrantes deste arranjo, a investigação configura-se de natureza qualitativa, desenvolvida de forma longitudinal, com cortes transversais, no período de 1990/2017, identificando o conteúdo, o contexto e o processo de mudança no APL. Os resultados apontam que a trajetória do APL é constituída de quatro períodos estratégicos, consolidando uma configuração de relações a partir de três grupos de atores, as empresas âncoras que ao estabelecerem laços fracos protagonizam os processos de inovação; as empresas sistemistas que densificam os laços fortes e verticais; e as demais empresas do APL, que complementam os laços fortes e horizontais destas relações. Também foram analisados os conflitos entre os diversos atores, a dinâmica da confiança entre as empresas e Conselho Gestor e os limites à constituição de sistemas orgânicos de governança.
\end{abstract}

Martinho Luís Kelm

Universidade Regional do Noroeste do Estado do Rio Grande do Sul

martinho@unijui.edu.br

Jéssica Casali Turcato

Universidade Regional do Noroeste do Estado do Rio Grande do Sul

jehturcato@hotmail.com

Jorge Oneide Sausen

Universidade Regional do Noroeste do Estado do Rio Grande do Sul

josausen@unijui.edu.br

Cátia Raquel Felden Bartz

Universidade Regional do Noroeste do Estado do Rio Grande do Sul

bartzcatiar@fahor.com.br

Recebido em: 12/04/2018. Aprovado em: 14/08/2020.

Avaliado pelo sistema double blind review

Avaliador científico: Elisa Reis Guimarães

DOI: 10.48142/2238-68902019v21n1-3p115130

\begin{abstract}
This study context is the interdependency of local and specific organizations factors in the sense of create sustainable competitive vectors. From this, a group of initiatives and relations emerge to organize and produce a minimum alignment between a set of companies from the Panambi-Condor/RS Post Harvest Local Productive Arrange (LPA), subject of this investigation. From the inquiry regarding the way in which the collaborative governance was operated in this environment, the study analyzed the way that the relations between different actors from APL were established and how they interfered on the system force as a whole. Based on the perception of the members of management committee and companies managers included in this arrangement, the investigation is qualitative in nature, developed in a longitudinal way, with cross-sections, in the period of 1990/2017, identifying content, context and APL displacement process. The results indicate that the LPA trajectory is composed of four strategic phases, consolidating a relationship configuration through three groups of actors, the anchor companies that, when establishes weak ties are involved in innovation processes; the systematic companies that densify the vertical and strong ties; and other LPA companies that complete strong and horizontal ties of these relations. The conflicts between several actors were also analyzed, beyond the dynamic of trust between the companies and the Director Board and also the limits to the constitution of organic governance systems.
\end{abstract}

Palavras-chave: Adaptação Estratégica. Colaboração. Laços Sociais. Relações Interorganizacionais.

Keywords: Collaboration. Interorganizational Relations. Social Ties. Strategic Adaptation. 


\section{INTRODUÇÃO}

O processo de mudança organizacional tornou-se natural na dinâmica das empresas contemporâneas e requisito para sustentar padrões superiores de competitividade no mercado, de modo a garantir a sobrevivência das empresas. Compreender a importância dessas mudanças envolve considerar o caráter intermitente e mutável do ambiente (TENÓRIO et al., 2013). Desse modo, esse processo conduz a uma adaptação constante e cada vez menos esporádica e ocasional, uma vez que este movimento resulta na elevação da velocidade com que as informações são difundidas e são alteradas, reduzindo o tempo de resposta disponível para a empresa reposicionar-se frente às mudanças ambientais.

Quando esta dinâmica é analisada em termos de populações de empresas atuando de modo articulado, como é o caso de redes ou arranjos produtivos, este quadro se torna ainda mais complexo na medida em que se agrega ao caráter efêmero dos elementos específicos de cada organização, os fatores que, por uma ação integrada, também deveriam gerar diferenciais competitivos e que também necessitam de uma permanente adaptação, sem desconhecer muitos movimentos miméticos que se tornam mais evidentes (DIMAGGIO; POWELL, 1983).

Desta forma, compreender o vigor competitivo de um sistema de empresas implica em uma análise de sua capacidade de adaptação a estes diversos fatores e exige o entendimento do modo como o sistema e seus integrantes foi historicamente se configurando e se sustentando, nesse caso, não mais limitado por relacionamentos permeados puramente pela competitividade direta entre empresas de um território, mas pela possibilidade de ações conjuntas e articuladas entre essas empresas de modo a buscar um aprendizado e posicionamento competitivo enquanto população de empresas (ANSELL; GASH, 2008; GERLAK; HEIKKILA, 2007).

Estes formatos organizacionais colaborativos tornaram-se uma estrutura recorrente para a busca da competitividade nas últimas décadas e uma estratégia para que as organizações realizem ações coletivas e cooperadas no sentido de contemplar os interesses coletivos na busca por competitividade individual. Um exemplo deste novo modelo organizacional são os Arranjos Produtivos Locais - APL's, que são aglomerações ou concentrações territoriais e setoriais de agentes econômicos, políticos e sociais em torno de uma atividade econômica específica, nas quais se estruturam vínculos e relações de interação, interdependência, cooperação e aprendizagem, voltadas para o enraizamento da capacidade inovativa contínua, essencial para geração de competitividade e sustentabilidade dos seus membros, como também para a promoção do dinamismo econômico local (HUMPHREY; SCHMITZ, 1996; WOITCHUNAS et al., 2018).

Este artigo analisa o processo de mudança e adaptação estratégica de um arranjo produtivo local, o APL Pós-colheita de Panambi-Condor, no Rio Grande do Sul, segundo as estratégias coopetitivas adotadas sob a perspectiva de um modelo colaborativo de governo, e o modo como as alianças e relações entre os integrantes foram sendo constituídas e impactando na efetividade do arranjo como um todo. Em síntese, envolve analisar a capacidade deste sistema em converter um movimento cooperativo em fundamentos competitivos para as partes e também para seu conjunto e os limites destas iniciativas.

O sistema em análise é composto por um conjunto de 80 empresas dos mais variados portes e que atendem as regiões agrícolas do Brasil e de países da América Latina, produzindo $65 \%$ dos equipamentos agrícolas nacionais vinculados a pós-colheita de grãos (BASSO; TRENNEPOHL, 2012). O objetivo do APL, segundo seus atos constitutivos, é promover a troca de experiência de gestão, a geração de tecnologia na fabricação de produtos e a busca de mercado para o setor, como um meio de potencializar os ganhos individuais e aumentar a competitividade das empresas pela ação coletiva. Desde sua criação, no ano de 2003, o APL tem exercido um papel relevante no processo de desenvolvimento socioeconômico da região. Compreender seus principais períodos estratégicos e o modo como as estratégias competitivas (BENGTSSON; KOCK, 2000) foram adotadas no seu processo de mudança e adaptação, pode contribuir para que seus participantes pavimentem as próximas etapas de sua trajetória. Estes fatores são ainda uma importante fonte de referência para este modelo organizacional em ascensão no Brasil e com um vasto campo de pesquisa a ser desenvolvido.

\section{REFERENCIAL TEÓRICO}

\subsection{Teoria da Agência}

Uma questão que nas últimas décadas tem recebido grande atenção do meio organizacional e acadêmico envolve os diversos conflitos originários dos processos de delegação e de separação da propriedade e da gestão. Debatidos no escopo da denominada Teoria da Agência (JENSEN; MECKLING, 1976), este tema ganhou destaque em função de um conjunto de escândalos corporativos (COSTA; WOOD Jr, 2012) ocorridos nas últimas décadas 
que se originaram do uso inadequado de processos de delegação de responsabilidades e que acabaram comprometendo expectativas de subgrupos de atores organizacionais.

Coase (1937) foi pioneiro ao estabelecer as bases deste com a discussão conceitual sobre o funcionamento das firmas sistematizada na Teoria da Firma. Posteriormente, entre os anos 1970 e 1980, as concepções de Williamson (1996), sobre a Teoria dos Custos de Transações ampliaram o escopo de análise que foram também complementadas por Jensen e Meckling (1976) no debate sobre os conflitos e custos de agência, todas estas abordagens aperfeiçoaram e tornaram mais complexos os fundamentos do que atualmente compõem os mecanismos de governança corporativa.

Estes mecanismos de governança buscam constituir elementos que, considerando o conflito potencial existente entre principal e agente, possam reduzir ações oportunistas ou decisões de grupos que comprometam extratos específicos de atores dentro da organização. Assim, o debate tem como referência um contexto de oportunismo dos agentes, racionalidade limitada, contratos incompletos e a incerteza na tomada de decisão organizacional (BARNEY; HESTERLY, 2012).

Os conflitos de agência partem da premissa de que existe divergências de interesse entre diversos agentes organizacionais na medida em que a maximização de funções objetivo pessoais e organizacionais podem ter estratégias de otimização ou resultados conflitantes entre si (JENSEN; MECKLING, 1976; SILVEIRA, 2015).

Acompanhando as abordagens competitivas mais recentemente, as concepções de estudo do desempenho da firma voltaram-se à investigação de ações articuladas que almejam estabelecer iniciativas de colaboração entre as organizações de um determinado território de modo a beneficiar uma população de entidades. Estas interações geralmente são formadas por trocas laterais ou horizontais, com hierarquia reduzida e fluxos interdependentes, recíprocos e cooperativos. As formas de colaboração interorganizacional são elementos chave para a teoria da agência e também para a compreensão do próprio processo de cooperação como estratégia na busca pela competitividade organizacional, uma vez que a colaboração entre empresas também se presta à adoção de comportamentos oportunistas, como por exemplo, a possibilidade de existência de free riders (BARNEY; HESTERLY, 2012).

Essas relações colaborativas são igualmente permeadas por conflitos de interesses, objetivos ambíguos, incertezas, contratos incompletos em um contexto geralmente marcado pela informalidade. Entende-se que é fundamental que se aprofunde os estudos no aperfeiçoamento de mecanismos que minimizem a materialização destes "conflitos potenciais" de modo a garantir um tratamento equitativo dos diversos atores organizacionais e stakeholders (BARNEY; HESTERLY, 2012; SILVEIRA, 2015). Essas relações colaborativas são igualmente permeadas por conflitos de interesses, objetivos ambíguos, incertezas, contratos incompletos em um contexto geralmente marcado pela informalidade. Entende-se que é fundamental que se aprofunde os estudos no aperfeiçoamento de mecanismos que minimizem a materialização destes "conflitos potenciais" de modo a garantir um tratamento equitativo dos diversos atores organizacionais e stakeholders (BARNEY; HESTERLY, 2012; SILVEIRA, 2015).

Conforme Barney e Hesterly (2012), os formatos organizacionais de gestão coletiva e colaborativa, tal como o Arranjo Produtivo Local objeto deste estudo, são estruturas híbridas de organização menos hierárquica que conduzem a modelos de governança em que as organizações obtêm ganhos por meio da cooperação. Os potenciais conflitos de agência que poderão emergir desse tipo de relação são significativamente elevados e justificam a discussão acerca da habilidade desses atores sociais em induzir a cooperação dos demais atores em uma relação que demanda delegação de tarefas permeadas por interações que exigem confiança, interdependência e colaboração para serem exitosas.

\subsection{Teoria da Habilidade Social}

Considerando que o estudo problematiza a capacidade de um APL em alinhar e equilibrar interesses particulares para uma ação coletiva convergente, é fundamental que se busque elementos do modo como esta dinâmica coletiva, e pretensamente colaborativa, pode ser investigada, preocupação igualmente levantada por LUBELL, et al. (2017) quando investigam este aspecto em sistemas complexos. Fligstein (2007), com a Teoria da Habilidade Social, trouxe uma abordagem contemporânea para analisar a reprodução e a mudança social diante da teoria sociológica clássica. Pela visão clássica, a ação dos atores é explicada pela estrutura social a qual o indivíduo está inserido, o que torna esta pessoa fruto desta estrutura e com um limitado poder de transformação de seu mundo social. Pela corrente das teorias "neo-institucionalistas" das ciências sociais, reconsidera-se o papel desta estrutura e ganham destaque as possibilidades de ação independente que cada pessoa exerce na reprodução de sua vida social. Estas teorias convergem na medida em que relacionam a construção de ordens sociais locais com um debate sociológico abrangente entre atores e estruturas. 
No momento em que os atores passam a ter poder de ação e assumir uma função independente da estrutura, surge o que Fligstein (2007) denomina de habilidade social. A visão da ação se relaciona com os atores que tentam obter a cooperação de um conjunto de outros atores para alcançar fins coletivos, de modo que, para induzir este comportamento os atores-chave - ou atores estratégicos devem ter a necessária habilidade para que esses objetivos coletivos sejam alcançados.

Estas ordens sociais locais são também conceituadas como "campos" (BOURDIEU, 1977; 1996), ou ainda, como "campos organizacionais" (DIMAGGIO; POWELL, 1983). Os campos ocorrem em situações nas quais grupos organizados de atores reúnem-se para expor ideias e desenvolver ações, criando instituições como consequência da interação social entre os atores que se confrontam no campo. Bourdieu $(1977,1996)$, aponta que os campos são espaços estruturados e conflituosos, em que os agentes interagem e competem por uma posição de autoridade e poder. Segundo o autor, o poder, seria a capacidade de impor as próprias ambições a outros agentes sociais de modo que a relação social entre esses agentes ocorra conforme o desejo de quem a impôs. A abordagem da habilidade social é fundamental para compreender a formação dos campos e sua dinâmica de poder, uma vez que, instituir e transformar campos pode ser decorrência da habilidade social dos atores que orientam o comportamento estratégico do grupo (FLIGSTEIN, 2007).

A teoria da habilidade social se assemelha ao debate instigado por Giddens (1984) com a Teoria da Estruturação ${ }^{1}$, quando o autor trata da relação entre agente e meio social pela integração entre ação-estrutura por meio de uma visão dinâmica da ação social que está em constante processo de estruturação e reestruturação. Para

${ }^{1}$ A Teoria da Estruturação é proposta por Giddens em 1984 com a publicação do livro "A constituição da sociedade". A estrutura para Giddens (1984, p. XXXV - introdução) é "o conjunto de regras e recursos implicados, de modo recursivo, na reprodução social; as características institucionalizadas de sistemas sociais têm prioridades estruturais no sentido de que as relações estão estabilizadas no tempo e no espaço. A 'estrutura' pode ser conceituada abstratamente como dois aspectos de regras: elementos normativos e códigos de significação. Os recursos são também de duas espécies: recursos impositivos, que derivam da coordenação da atividade dos agentes humanos, e recursos alocativos, que procedem do controle de produtos materiais ou de aspectos do mundo material". Isso quer dizer que, "a constituição de agentes e estruturas não são dois conjuntos de fenômenos dados independentemente - um dualismo -, mas representam uma dualidade. A dualidade da estrutura é sempre a base principal das continuidades na reprodução social através do tempo e espaço. A dualidade pressupõe a estrutura como meio e resultado da conduta que ela recursivamente organiza. As propriedades estruturais de sistemas sociais não existem fora da ação, mas estão cronicamente envolvidas em sua produção e reprodução" (O'DWYER; MATTOS, 2010, p. 616). ele, a estrutura remete ao conjunto de regras e recursos que auxiliam na constituição e regulação da reprodução social, configuradas pela conduta dos atores, uma vez que, alguns desses atores sociais terão maior poder de influenciar o comportamento dos demais. Baseado nessas premissas, "as práticas sociais podem ser entendidas como procedimentos, métodos ou técnicas hábeis executadas apropriadamente pelos agentes sociais utilizando-se regras e recursos." (O’DWYER; MATTOS, 2010, p. 616).

\subsection{Governança Colaborativa: Um Modelo de Governo para as Estratégias Coopetitivas}

A governança em aglomerações de empresas é determinante para o aumento da interdependência entre esses atores e está relacionada à coordenação e controle das ações e dos projetos, no sentido de desenvolver e especializar os membros do arranjo, promovendo a produção compartilhada e estimulando a cooperação e inovação. Para Suzigan, Garcia e Furtado (2007, p. 425), é a "capacidade de comando ou coordenação que certos agentes (empresas, instituições, ou mesmo um agente coordenador) exercem sobre as inter-relações produtivas, comerciais, tecnológicas e outras, que acaba influenciando decisivamente o desenvolvimento do sistema ou arranjo local".

Estes novos tipos de arranjos empresariais exigem estruturas de governança capazes de conciliar os interesses paralelos ou distintos, a competição e a cooperação, bem como as relações autônomas e interdependentes, buscando planejar e executar de modo conjunto às ações para o desenvolvimento sinérgico dos envolvidos (VILLELA; PINTO, 2009; QUANDT, 2012). Villela e Pinto (2009), ao analisarem a governança nos APLS mencionam a heterogeneidade de interesse e o grau de confiança ainda incipiente entre os atores envolvidos, demonstrando a dificuldade de uma gestão social verdadeiramente participativa e deliberativa.

A governança colaborativa é difundida como uma forma de governo na qual a colaboração é o principal mecanismo de envolvimento nas relações entre atores públicos e privados, equilibrando os diferentes interesses desses atores (BODIN, 2017; BODIN; NOHRSTEDT, 2016) para aumentar o valor dos bens ou serviços oferecidos e obter ganhos competitivos (BARDACH, 2001), no intuito de efetivar as aspirações conjuntas e minimizar as assimetrias de poder e a influência das coalizões que possam surgir nesse processo (BARDACH, 2001; AGRANOFF, 2005; ANSELL; GASH, 2008; EMERSON; NABATCHI; BALOGH, 2012; BODIN, 2017) e gerar um processo compartilhado de aprendizado (ALVES et al., 2013) 
Os formatos organizacionais cooperativos possuem características próprias ambivalentes que unem competição com colaboração, ganhos de escala com ganhos de especialização e, principalmente, coordenação com flexibilidade (ASTLEY; FOMBRUN, 1983; ASTLEY, 1984). Segundo Berardo e Lubell (2016), a importância das formas coletivas frente aos modos individuais de adaptação organizacional utilizando o conceito de collective strategy construídas pela mobilização conjunta de recursos e formulação de ações pela coletividade das organizações.

Para essa relação complexa e ao mesmo tempo vantajosa atribui-se o termo coopetição (NALEBUFF; BRANDENBURGER, 1997; BENGTSSON; KOCK, 2000), que surge quando várias organizações competem e cooperam entre si de modo simultâneo. A complexidade está na contradição que existe nessa relação, pois, será cooperativa em determinadas atividades e competitiva em outros campos, uma vez que ambos os elementos (cooperação e competição) se tornarem visíveis na relação entre os competidores. As trocas colaborativas permitem a criação de redes de relacionamentos, como ocorre nos arranjos produtivos, que favorecem o estabelecimento de laços sociais entre os atores. Bodin (2017) analisou os arranjos de governança colaborativa a partir de redes sociais-organizacionais colaborativas que compõem um sistema interativo entre distintos atores e concluiu que os tipos de laços sociais criados entre esses atores enquanto se envolvem em colaboração afetam diretamente os resultados do conjunto.

Granovetter $(1973 ; 1983)$ foi um dos precursores dessa abordagem, categorizando as relações sociais a partir dos conceitos de "laços fortes" e "laços fracos". Por laços fortes, entende-se as ligações nos relacionamentos entre atores com maior proximidade, maior intimidade a exemplo da maioria das relações no interior das famílias. Já laços fracos são as ligações com menor proximidade, mas que segundo o autor, tem uma grande possibilidade de enriquecer as partes com conhecimento e gerar inovações. Redes colaborativas fundamentadas em laços fortes são mais propícias para a solução de problemas de cooperação, em especial, questões de alto risco e ao desenvolvimento da confiança mútua devido à proximidade dos atores envolvidos e a tendência em constituir laços de amizade e confiança (BODIN, 2017). Em contraponto, laços sociais fracos entre atores com menor proximidade possuem maior alcance e propensão de atingir outros atores, favorecendo a capacidade de aprendizagem e inovação da rede (GRANOVETTER,
1973; 1983). Solucionar potenciais conflitos que poderão surgir da cooperação envolve também a capacidade de inovação da rede, nesse sentido, a inovação requer quebras de normas e percepções preestabelecidas encontradas em relacionamentos menos centralizados, uma vez que permite o surgimento de novas ideias e a difusão de conhecimento que são propagados por redes de relacionamentos colaborativos de maior amplitude (BODIN, 2017; BODIN; NOHRSTEDT, 2016).

Shipilov e Li (2012) rediscutem os conceitos originais de Granovetter (1973) aprofundando as pesquisas sobre o papel das tríades, que são relações estabelecidas entre três atores de uma cadeia de valor. Esta abordagem mostra-se útil para o presente estudo na medida que, em termos práticos, um arranjo produtivo é uma composição de tríades, com as mais diversas configurações. Neste contexto, também emerge o conceito de multiplexidade que decorre da horizontalidade ou verticalidade dos laços estabelecidos entre os atores destas tríades. Segundo estes autores, por laços horizontais pode-se entender como aqueles que unem atores que conectam duas firmas com papéis equivalentes, por exemplo, clientes de produtos semelhantes. Já, os laços verticais conectam diferentes estágios de uma cadeia de valor, como por exemplo, fornecedores e clientes.

Esta abordagem amplia as possibilidades de entrelaçamentos em um arranjo produtivo e, da mesma forma, eleva o desafio de viabilizar níveis razoáveis de convergência, principalmente nas relações verticais. Isto ocorre, pois, segundo Shipilov e Li (2012), na configuração de tríade, existe a possibilidade de uma relação na qual, por exemplo, o ator A estabelece laços de confiança com o ator B e com $\mathrm{C}$, mas que estes dois últimos atores $\mathrm{A}$ e $\mathrm{B}$ não interagem com a mesma fluidez. Esta configuração mencionada por Burt (1992) como buracos estruturais (structural holes) permite que o ator A gerencie o relacionamento entre B e $\mathrm{C}$ de acordo com seus interesses.

Neste relacionamento triádico, proposto inicialmente por Burt (1992), implica que dois nós podem não estar conectados diretamente, mas possuem um vínculo comum com uma terceira firma que tem o potencial de assumir o protagonismo de buraco estrutural, ocorrendo uma redundância por adesão, como demonstrado na Figura 1.

Esta terceira firma, na Figura 1, representada pela empresa âncora, pode fazer uso de sua posição privilegiada para induzir movimentos aos demais integrantes da relação, como por exemplo, ampliando o número de fornecedores de um determinado componente industrial que ela porventura necessite. 


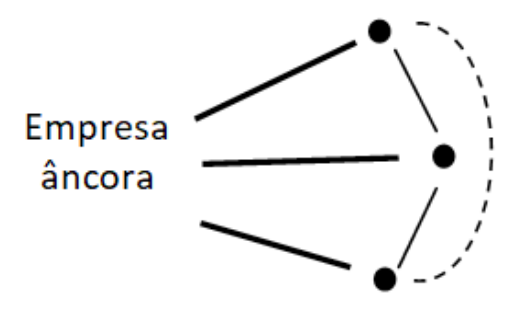

Redundância por coesão

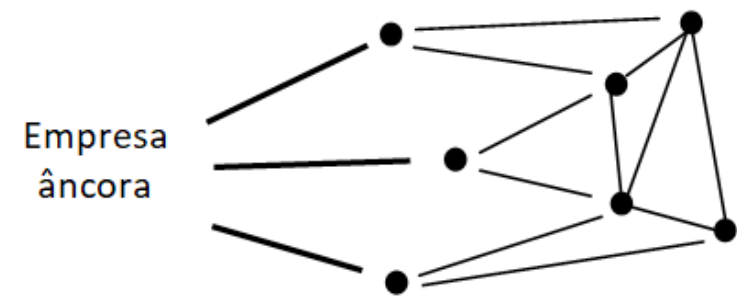

Redundância por equivalência estrutural

FIGURA 1 - A configuração dos buracos estruturais de um sistema social Fonte: Adaptado de Burt (1992)

Conforme Cassiolato e Szapiro (2002), ao tratar sobre arranjos organizacionais consideram-se além da cooperação, os processos de aprendizado, inovação e capacitação, fundamentais para a competitividade do aglomerado. Do mesmo modo, existem condicionantes que irão influenciar se o modo de governança irá produzir - ou não - um processo de colaboração exitoso, tais como: comunicação (ANSELL; GASH, 2008), construção da confiança mútua entre os agentes (ANSELL; GASH, 2008; EMERSON; NABATCHI; BALOGH, 2012; BODIN, 2017), interdependência e qualidade de liderança da rede (ANSELL; GASH, 2008; EMERSON; NABATCHI; BALOGH, 2012; BODIN, 2017), compromisso e compreensão compartilhada (ANSELL; GASH, 2008; EMERSON; NABATCHI; BALOGH, 2012).

\section{METODOLOGIA}

Para alcançar o objetivo proposto, o estudo envolveu a análise da percepção de um conjunto de atores integrantes do Comitê Gestor do APL Pós-Colheita PanambiCondor e de gestores de empresas participantes do arranjo, visando identificar e analisar os períodos estratégicos de mudança do APL e como se configuraram as relações entre as diversas organizações integrantes do projeto, no sentido de promover um movimento coopetitivo.

De natureza qualitativa, a análise adotou uma perspectiva longitudinal, procedendo com cortes transversais para a definição dos períodos de mudança estratégica. Um estudo qualitativo exige um trabalho de persistência e aprofundamento por parte do pesquisador, o qual busca, de forma indutiva, estabelecer e descrever a história de seu objeto de pesquisa (RICHARDSON, 2017). A análise longitudinal permite a observação da evolução da unidade de análise, na direct research (MINTZBERG, 1979), a pesquisa segue os seguintes passos: a) coleta de dados, b) inferência dos períodos e das estratégias de mudança; c) análise dos períodos de mudança e d) análise teórica do estudo.

A pesquisa adotou um caráter descritivo, sendo explicitados os traços característicos das interações entre os atores, assim como funções e outros aspectos que possibilitam a compreensão dessas relações para a descrição dos processos de mudança e adaptação estratégica do APL e o modo como as relações entre as firmas interferiram neste processo. A coleta e análise dos dados considerou ainda o preconizado por Pettigrew; Ferlie e Mckee (1992) analisando o conteúdo, o contexto e os processos de mudança do APL. A partir deste ponto procedeu-se a interpretação do processo de mudança do APL, baseado nas referências teóricas que abordam a temática da governança colaborativa e das estratégias coopetitivas.

No tocante aos procedimentos técnicos, constitui-se em um estudo de caso singular devido ao objetivo da pesquisa de identificar os processos de mudança e de adaptação estratégia organizacional do APL PanambiCondor. Trata-se, também, de um estudo de campo e documental, uma vez que os pesquisadores realizaram visitas ao comitê gestor do APL, entrevistas e análise de documentos.

A coleta dos dados foi realizada por meio de entrevistas semiestruturadas junto a seis gestores que articulam a gestão e as estratégias desde a constituição do APL, que se iniciou no ano de 2003 e perdura até o momento. Os dados secundários foram coletados de registros internos envolvendo documentos, planos institucionais, atas das reuniões de modo a promover o resgate histórico da trajetória do APL.

Conforme retratado na Figura 2, o estudo envolveu duas perspectivas de análise, uma enfocando o próprio Arranjo Produtivo Local e outra seus atores. 


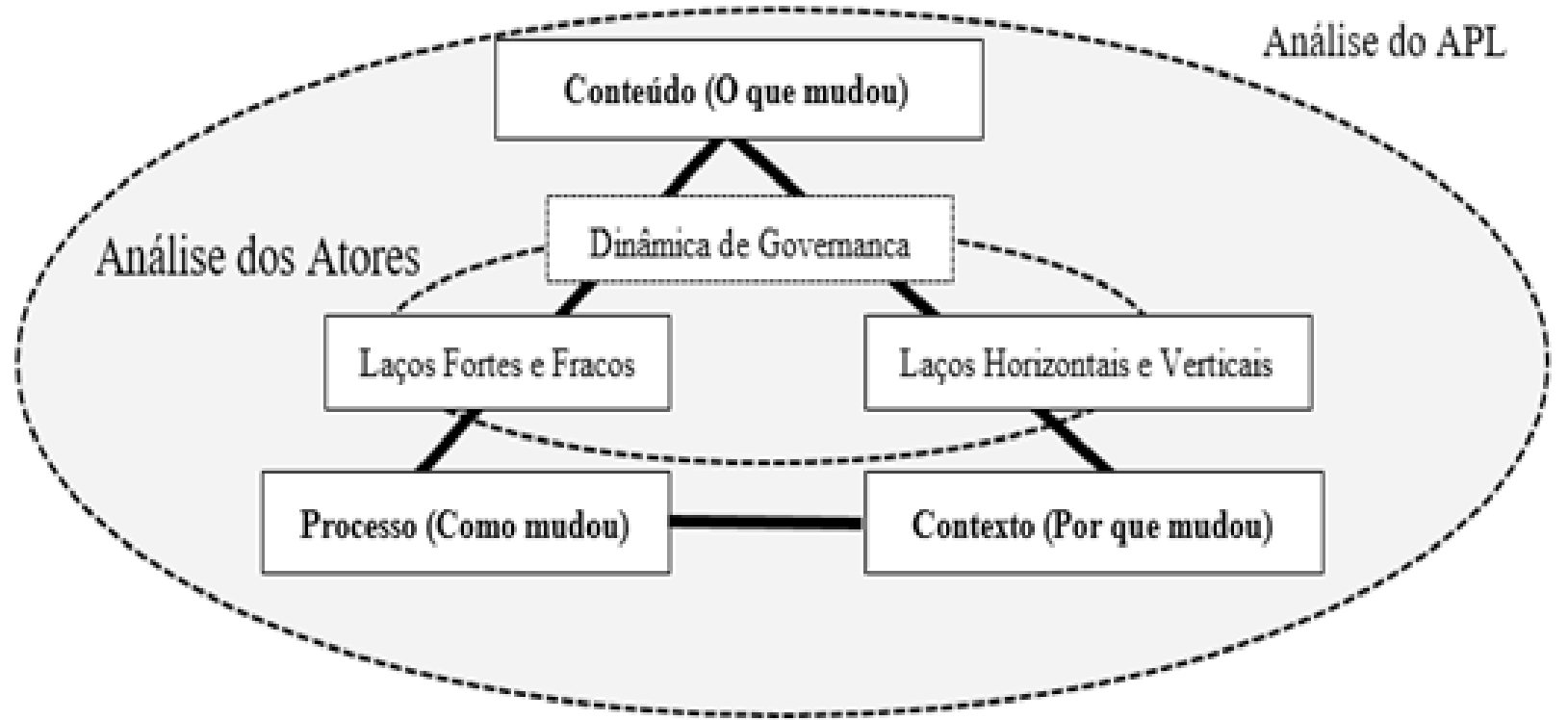

FIGURA 2 - Modelo de análise

Fonte: Sistematizado pelos Autores

Para as duas perspectivas de análise, adotou-se o método da Direct Research (MINTZBERG; 1979), no intuito de elaborar uma cronologia com os eventos marcantes para o APL, delimitando os períodos que ocorreram mudanças e adaptações estratégicas para então identificar os grandes períodos estratégicos. Em continuidade, o estudo foi aprofundado na perspectiva dos atores que integraram este processo, abarcando a dinâmica de governança, o modo como os laços fortes e fracos foram constituídos e repercutiram no APL (GRANOVETTER, 1973; 1983), e o modo como os laços horizontais e verticais foram acompanhando esta dinâmica (SHIPILOV; LI, 2012; BURT, 1992).

\section{ANÁLISE DOS PERÍODOS DE MUDANÇA E ADAPTAÇÃO ESTRATÉGICA DO APL PÓS- COLHEITA}

Conforme destacam Pacheco e Arruda (2012), a matriz produtiva dos municípios de Panambi e Condor tem sua origem no processo de colonização do seu território, pois, era tarefa da pequena população que habitava a região fabricar instrumentos para que os colonos trabalhassem a terra. Foi a partir deste contexto que surgiram as primeiras oficinas coloniais que ao longo dos anos floresceram e se transformaram em empresas com tecnologia de ponta, constituindo-se em referências a nível nacional e internacional em inovação tecnológica.
Desta forma, a mobilização das organizações do APL em estudo, para planejar de modo cooperativo ações e estratégias que as mantivessem competitivas no mercado, foi iniciada em meados de 1990, um marco para que, posteriormente, fosse constituída uma estrutura formal de arranjo produtivo local, recebendo a denominação de APL Pós-colheita. A trajetória de constituição de um novo modelo de interação das organizações definiu a abrangência da presente investigação, a qual circunscreve-se à análise dos processos de mudança e adaptação estratégica ocorridas no período de 1990 a 2017, que se configuraram nos períodos estratégicos a seguir analisados.

\subsection{Período Estratégico I - Articulação Coletiva Pré-APL (1990 a 2002)}

Durante este primeiro período, as empresas, entidades representativas do setor e do governo, bem como as instituições de ensino da região, já mantinham um processo embrionário de articulação, mesmo que de maneira informal. Segundo os entrevistados, essas empresas necessitavam de conhecimento, inovação e desenvolvimento tecnológico para acompanhar as transformações do mercado que ocorria na época, mas como não estavam articuladas de maneira formal, não conseguiam ser beneficiadas por políticas públicas específicas. Conforme um dos entrevistados, "a aglomeração já existia há muitos anos, as empresas interagiam para manter alunos no ensino profissionalizante e promover viagens em busca de tecnologia, adquirir equipamentos, entre outros". 
Como uma das soluções encontradas para amenizar essas deficiências institucionais, as empresas buscaram junto às instituições de ensino técnico e superior instaladas nos municípios, profissionalizar o ensino e capacitar os jovens e os trabalhadores residentes no local de acordo com suas necessidades. A atuação destas instituições de ensino, somado ao apoio dos poderes públicos municipais, cumpriu um papel fundamental no apoio à difusão do conhecimento e geração de algumas inovações, principalmente em termos de capacitação de pessoas e melhoria de processos de produção.

Paralelo a este processo, ainda na década de 1990 iniciava-se a qualificação das empresas para atuação em novos patamares competitivos que suplantassem o mercado local e regional. No município de Panambi/RS, esse processo ficou mais denso com a chegada de instituições integrantes do "Sistema S" (Sesi, Senai, Sebrae e Sesc), que fortaleceram a multiplicação de conhecimento e capacitação profissional, sendo que, posteriormente, essas instituições seriam também essenciais à constituição do APL, integrando seu comitê gestor e de governança. Esses atores estratégicos, também denominados por terceiras partes por integrarem o arranjo mesmo não compondo diretamente a cadeia de valor do segmento, foram cruciais na promoção da cooperação das demais instituições, dada sua neutralidade competitiva e vinculação com órgãos de fomento, que acabaram por intermediar o aporte de recursos para os primeiros anos do APL. Segundo Ring e Van de Ven (1994), a existência destas "terceiras partes" pode, algumas vezes, substituir estruturas e contratos formais, pois, tem um potencial de atuar como mediadores de confiança nestas fases iniciais de construção de projetos colaborativos entre firmas, como também foi posteriormente percebido por Woolthuis et al. (2013) e Berardo (2014) em pesquisas sobre o papel destes agentes na organização de agrupamentos de empresas e condução de políticas públicas. Berardo e Lubell (2016) também pesquisaram o tema sob a perspectiva de como os limites cognitivos e restrições sobre a avaliação do cenário afetava a capacidade de engajamento dos atores e a influência de um agente de articulação.

Considerando que nesse período o arranjo ainda não havia sido formalmente constituído, a articulação acabou ocorrendo essencialmente devido à proximidade e as características comuns e/ou complementares entre as empresas. As relações entre os atores durante esse período foram sustentadas pela confiança e compromisso compartilhado, pois, não havia mecanismos formais de cooperação, cabendo aos primeiros articuladores transmitir os ideais do projeto, de modo que os conflitos que pudessem surgir dessa nova autoridade (liderança do APL) pudessem ser minimizados. Esse movimento foi facilitado por um histórico de convivência decorrente de todo o processo de colonização que, por meio da religião, clubes sociais e de serviços já produziam um processo de aproximação e convívio que, a partir deste momento, começa a ser transferido para as relações empresariais.

Analisando a estrutura das relações estabelecidas entre as firmas, é possível perceber que ainda não ocorre, de modo expressivo, a formação do que Granovetter (1973, 1983) denomina de laços fortes, embora um conjunto de grandes empresas locais começassem a estabelecer um conjunto de laços fracos que permitiram-lhes incorporar inovações aos produtos e processos e acessar novos mercados. Quando esta população de firmas é analisada segundo a perspectiva de Shipilov e Li (2012), é possível perceber a coexistência de laços horizontais e, em alguma medida, laços verticais que posteriormente serão densificados, na medida em que o APL foi se consolidando.

\subsection{Período Estratégico II - Criação do APL (2003 a 2007)}

Este período estratégico tem início de um movimento de empresas líderes do mercado que entendiam que seria fundamental uma maior densidade e sinergia da matriz produtiva local, seja para atuar de modo complementar, fornecendo componentes e materiais para estas empresas maiores, seja integralizando famílias de produtos ou criando uma identidade de imagem vinculada ao território em análise. A materialização desta visão evolui quando, em 2003, o SEBRAE recebe a incumbência de estruturar o APL Pós-Colheita, trabalho que foi auxiliado por um coordenador de projetos designado pela Agência Gaúcha de Desenvolvimento e Promoção do Investimento (AGDI), hoje denominada como Escritório de Desenvolvimento de Projetos, e que integra a estrutura da Secretaria de Planejamento, Governança e Gestão do Governo do Estado do Rio Grande do Sul. Segundo os atores ouvidos na pesquisa, esta tarefa foi facilitada pela predisposição dos empresários locais em constituir uma articulação regional que apoiasse a manutenção de suas posições competitivas.

O período foi marcado por um esforço de sensibilização junto a empresários para que aderissem aos objetivos e princípios do APL. Nesse momento, muitas empresas, principalmente as de pequeno e médio porte, vislumbravam no APL um potencial para conquistar 
novos mercados. "As empresas se uniram por fins puramente mercadológicos, pela possibilidade de serem mais competitivas, sendo esse o motor de partida, à competição", aponta um dos entrevistados. Esta percepção acabou compondo a narrativa articuladora do projeto, cabendo sempre lembrar que um conjunto de empresas, denominadas de "empresas âncoras", sempre zelou para que o grande grupo patrocinasse seus interesses específicos, fomentando uma ação mais massificada de modo a garantir a legitimidade do movimento.

Ainda com relação às motivações deste movimento, pode-se observar uma variante do que Burt (1992) e recentemente Burt; Kilduff e Tasselli (2013), denominaram e discutiram sobre os "buracos estruturais" os quais, diferente da proposição original na qual a empresa âncora, por sua posição privilegiada, determinaria as iniciativas das demais empresas, no caso do APL pós-colheita também as demais empresas buscaram se beneficiar da relação com o "nó" que constituía o buraco estrutural, convertendo este vínculo em estratégia para acesso a novos mercados e clientes. Embora estivessem em uma posição mais frágil frente a estes grandes players, seus movimentos constituíram uma estratégia bastante nítida de, pela rede de relações e pela reestruturação dos laços verticais com uma empresa âncora, ampliar sua capacidade competitiva.

Outro aspecto que chama atenção no comportamento das "empresas âncoras", é que se o movimento destas empresas for analisado pelos conceitos apresentados por Granovetter (1973; 1983), no quais os laços fortes refletem as relações mais próximas de estabilidade e segurança e os laços fracos refletem relações mais esporádicas, mas determinantes dos processos de inovação, percebe-se um movimento de entidades com bons relacionamentos em termos dos laços fracos, buscando constituir e fortalecer um ambiente local que, em tese, seria marcado pelos laços fortes. Pôde-se ainda depreender da análise que o fortalecimento dos laços fortes, teve duas perspectivas: em primeiro lugar, significava constituir uma base local competitiva que pudesse dar suporte ao crescimento das empresas âncoras; em segundo lugar, também trazia como expectativa para as pequenas e médias empresas para um compartilhamento de fatores de competitividade obtidos pelos laços fracos por estas empresas âncoras, seja na forma de novas tecnologias e acesso a mercados ou processos de produção.

As primeiras iniciativas para constituição do APL envolveram a criação do comitê gestor como um instrumento de governança e a elaboração do plano estratégico, com a formalização do compromisso de cooperação do grupo, em buscar desenvolver este APL. Como já havia sido identificado por Woolthuis et al. (2013), também nesta experiência o comportamento de um conjunto de "terceiras partes" foi determinante para a evolução deste Arranjo Produtivo Local, por possuírem legitimidade e neutralidade frente aos integrantes diretos do setor produtivo. Esta afirmação se comprova também pelo fato de que a maior parte dos membros constituidores do comitê gestor ainda permanece no quadro, entre os quais as Associações Comerciais e Industriais dos municípios, a Associação Centro de Inovação Tecnológica, o Escritório de Desenvolvimento de Projetos, as escolas de formação técnica e as instituições de ensino superior, as prefeituras dos municípios e os integrantes do Sistema S (Sesi, Senai, Sebrae e Sesc).

O protagonismo das empresas do APL foi evidenciado em diversas iniciativas que impactaram, não somente nas empresas participantes, mas construíram uma identidade local que, de diferentes modos, foi sendo apropriado por todas as entidades participantes. Um fator que, segundo os entrevistados, influenciou positivamente a imagem do APL foi a melhoria de performance, em termos de resultado econômico e financeiro e desenvolvimento de capacidades organizacionais (GUERRA; TONDOLO; CAMARGO, 2016).

Como idealizadoras do APL e promotoras do desenvolvimento e cooperação das empresas do arranjo, cada instituição que compunha o comitê gestor possuía funções elementares, tais como na articulação das ações, na formação profissional e capacitação das empresas, deliberação sobre captações de recursos ou na participação em ações conjuntas que garantissem estratégias coopetitivas ao grupo. A mobilização conjunta permitiu o compartilhamento de experiências de cooperação no sentido de consolidar o APL e viabilizar trocas na prestação de serviço e utilização de máquinas, prospecção de mercado, visita e exposição em feiras nacionais e internacionais, desenvolvimento de produtos, cursos de formação e capacitação, central de compras e negociações, entre outros.

Esse segundo período estratégico envolveu a constituição formal do APL e articulação para a formulação das estratégias coopetitivas (BENGTSSON; KOCK, 2000; ANSELL; GASH, 2008), dando início as primeiras ações para a captação de recursos e planejamento e envio de projetos para órgãos financiadores. Devido a uma crise no setor agrícola entre o período de 2004 a 2006, decorrente de uma estiagem com forte impacto negativo nos resultados das indústrias, as vendas caíram drasticamente, implicando em uma redução de empregos, migração de profissionais qualificados para outras regiões e um contingenciamento 
no nível dos investimentos, tanto em termos do APL, como também nos projetos específicos das empresas. Essa situação dificultou a continuidade da atuação do APL no mesmo patamar, porém a interdependência entre os membros, assim como o compromisso compartilhado do grupo, criou um clima de engajamento no sentido de superar esse período de crise e utilizar a articulação que possuíam para a busca de soluções.

O formato de APL oportunizou que seus membros, principalmente a partir de seu comitê gestor, construíssem um sistema de laços fortes que foi essencial para que se mantivesse um alinhamento de iniciativas. Este foi um comportamento observado em todos os períodos estratégicos do APL, mas sobressaiu-se em um momento de crise como o vivido neste período, em que o comitê gestor necessitou utilizar de seu networking para a captação de recursos externos, evidenciando a importância do APL enquanto instância de articulação e cooperação (PACHECO; ARRUDA, 2012). A atuação conjunta e o arrefecimento da crise permitiram que houvesse uma caminhada razoavelmente unida do grupo para o período posterior, agora já com o mercado novamente aquecido. Isso acabou ocasionando que, muito dos projetos concebidos durante aquele período de crise, começassem a ganhar força e fossem aprovados no período seguinte, sendo um dos fatores determinantes para que o terceiro período estratégico fosse de crescimento de mercado.

Por fim, destaca-se um grande comprometimento na construção de um modelo de governança substancialmente colaborativo, sendo que nesse segundo período, a habilidade do grupo gestor foi vista como fundamental na busca pela cooperação de inúmeras empresas e instituições. Apesar deste empenho do grupo gestor do APL, a situação foi paulatinamente se complexificando nos períodos seguintes, uma vez que havia, além das empresas precursoras com alguma experiência de ação colaborativa, novas organizações ingressantes no bojo deste clima positivo, algumas sem esta visão mais colaborativa. Segundo um dos entrevistados, “... essa busca de mercado que estabeleceu um grau de sinergia entre as empresas, também, pela possibilidade de uma interação maior entre elas". Por outro lado, a agregação de novos atores também trouxe interesses que não necessariamente eram supridos pelo simples ingresso formal ao APL, gerando um duplo desconforto: por um lado, os novos entrantes muitas vezes não percebiam imediatamente os benefícios de participar do grupo e, por outro lado, abria-se a possibilidade de um posicionamento free-rider que gerava inquietação e desconfiança nos membros fundadores.

\subsection{Período Estratégico III - Crescimento do Mercado (2008 a 2014)}

O terceiro período estratégico foi muito bem demarcado na pesquisa e caracteriza-se por um importante aquecimento do mercado consumidor e consolidação de muitas ações integradas das empresas participantes do arranjo. As possibilidades de escolha estratégica nesse período foram altas, devido justamente a esse aquecimento do mercado. Tanto as empresas quanto o comitê gestor, tiveram a possibilidade de buscar estratégias coopetitivas de distintas formas, devido a maior capacidade de recursos, fato que de certa forma reflete um quadro de elevado determinismo ambiental (HRENINIAK; JOYCE, 1985), ao qual o arranjo produtivo local e suas empresas estavam expostos.

Como já demarcado, o período foi caracterizado pelo superaquecimento do mercado, em especial do setor agropecuário, resultado da maior liberação de recursos pelos governos para consecução de políticas públicas de fomento aos APL's e de linhas de crédito ao produtor rural (IPEA, 2014). Este movimento gerou uma busca por qualificação de mão-de-obra, e levou a instalar-se na região um Instituto Federal de Educação com potencial para ofertar vagas que preenchessem essa lacuna e com o desafio de formatar um curso técnico pós-colheita, até então não existente. Nesse sentido, a implantação desse Instituto contou com apoio dos membros do comitê gestor e posteriormente o próprio Instituto passou a constituir este Comitê.

Como a ampliação das possibilidades de formação profissional, também se evidenciaram outros importantes avanços no período que foram atribuídos a ação do APL e que se refletiram na melhoria da competitividade das empresas participantes, mesmo que esta relação não pudesse ser linearmente comprovada. Uma iniciativa mencionada foi à publicação dos resultados de uma pesquisa de mercado e plano estratégico de fomento à agricultura e à estruturação nacional de armazenagem de grãos, nessa pesquisa foi realizado um mapeamento da capacidade instalada de armazenagem, evolução da produção de grãos e a necessidade de recursos financeiros para armazenagem. A pesquisa permitiu que o APL, ao possuir dados concretos da realidade do setor no País, buscasse apoio para as políticas públicas e condução de novos projetos. Um amplo conjunto de iniciativas foi sendo concretizadas e socializadas, denotando uma elevada habilidade do comitê gestor em gerar fatos que evidenciassem a pertinência deste modelo de governança. Mais do que uma imagem positiva, foi possível produzir entendimentos dos diversos 
participantes que foram paulatinamente consolidando os laços fortes (GRANOVETTER, 1973, 1983) que permitiram ações em bloco do APL. Este movimento corrobora com os resultados recentes do estudo de Gerlak e Heikkila (2007) que, ao discutirem a formação os laços sociais em arranjos colaborativos, identificaram o papel positivo da constituição de estruturas formais na busca do aprendizado coletivo. Apesar disto, estes autores já alertavam sobre os limites deste aprendizado enquanto compartilhamento de conhecimento e não necessariamente com a geração de processos disruptivos, típicos de inovações mais profundas, os quais exigem uma importante interação com atores fora deste círculo mais próximo.

O fortalecimento das relações do grupo e a melhoria da autoestima das empresas por participarem de um projeto de tamanha visibilidade, não conseguiu ultrapassar uma dimensão local e mais conservadora, fato convergente ao reiterado por Bodin (2017). A realidade observada no APL confirma a tese de que as grandes mudanças tecnológicas, os saltos competitivos e estratégias suprarregionais ainda permaneceram majoritariamente restritos àquelas organizações que possuíam uma rede de relações mais diversificada, embora não tão densa (laços fracos).

Mesmo com essas ressalvas, esse crescimento permitiu o desenvolvimento de um grupo de empresas que, em um período relativamente curto, progrediu para um status de médio porte, geralmente atuando em nichos específicos e emergentes. Esse fato refletiu-se em uma modificação dos protagonistas internos do APL, uma vez que o Arranjo passou a ser conduzido, principalmente, por gestores dessas empresas emergentes, sendo que as empresas denominadas "âncoras" e detentoras de uma maior variedade de laços fracos acabaram relativizando suas participações nessa articulação e atuando mais como apoio nas ações ou, em outras palavras, "franqueando" seu nome ao APL. Já as empresas de pequeno e médio porte entendiam que por meio dessa articulação coletiva fosse possível alcançar novos mercados e obter ganhos competitivos maiores. Este fenômeno já havia sido observado por Kühl (2012), ao investigar a colaboração entre empresas do setor eletrônico no Brasil.

O crescimento das denominadas "empresas âncoras" e as mudanças nos processos produtivos a partir da expansão de metodologias como o lean thinking criou um grande mercado para empresas sistemistas, vinculados a estes grandes players industriais. "Ser um integrante deste grupo, sempre foi visto como uma forma de aproximação, de acesso à informação e ampliação de oportunidades, mesmo que para clientes locais", disse outro entrevistado. Este comportamento é que Shipilov e Li (2012) classificam como laços verticais e corrobora com os resultados já observados por Zoltan (2010), sobre pequenas organizações que buscam, na interação com outras empresas, preferencialmente àquelas vinculadas às tecnologias de ponta, o caminho para internalização de inovações a baixo custo. Esta estratégia, entretanto, nem sempre é exitosa (BRETTEL; CLEVEN, 2011), visto que as empresas que operam em níveis de alta performance nem sempre se dispõem a compartilhar suas inovações com alguns parceiros.

Este período, apesar de caracterizar-se pela expansão e crescimento, não foi livre de problemas de relacionamentos interfirmas. Mesmo que os conflitos explícitos fossem episódicos, um desafio que marcou a ação do grupo gestor foi o de gerenciar as "vaidades" de alguns empresários e também os ruídos, frutos da agressividade existente entre empresas do mesmo porte, principalmente quando integrantes do mesmo ramo de atividade, evidenciando de certa forma o que havia sido sinalizado por Day et al., (2013). Em períodos de recessão e adversidades, muitas dessas vaidades e conflitos acabam sendo colocados em suspenso para que se lute conjuntamente por uma causa maior, mas eles permanecem latentes. Este comportamento de focar na proteção e sobrevivência em períodos de adversidades é típico dos relacionamentos mais próximos, quase familiares, que formam os "laços fortes" de cada ator. O fortalecimento destes laços muitas vezes acaba turvando a visão para os verdadeiros focos de perigo que podem advir de outros contextos ou atores, fora deste círculo mais íntimo, e que muitas vezes passam despercebidos por este comportamento autocomplacente e de proteção mútua quase irrestrita.

Geralmente em períodos de maior crescimento, essas vaidades vêm novamente à tona como depreende-se da fala de um dos entrevistados quando este afirma que “... ao mesmo tempo em que o município e as empresas têm orgulho do APL e de ser reconhecida como cidade das máquinas existe uma disputa acirrada entre eles, pois, há várias empresas pequenas e médias que fornecem componentes e disputam entre si dentro do APL". "Ao mesmo tempo em que se reúnem em torno de uma mesa, existe um silêncio velado", aponta outro entrevistado. Para amenizar esse conflito e disputa de poder entre competição e cooperação, os membros do comitê gestor tiveram de desenvolver habilidades sociais e conduzir ações para retomar ao ambiente de cooperação. Este ponto que já havia sido observado no estudo de Bodin (2017), no caso do APL pós-colheita, fez com que o equacionamento dos conflitos no escopo da governança colaborativa tenha 
ficado restrito a relações interpessoais, visto não existirem ainda instrumentos e mecanismos de controle social que pudessem operar de modo relativamente autônomo.

\subsection{Período Estratégico IV - Crise e Recessão (2015 a 2017)}

Na sequência de um período de crescimento, iniciase uma fase na qual as estratégias relacionam-se ao enfrentamento e superação de um momento de crise e recessão em todo o País. O apoio governamental, que havia sido fundamental para o desenvolvimento do APL no período anterior sofreu uma drástica redução o que também repercutiu na diminuição na liberação de crédito ao produtor rural que, por sua vez, redundou em uma forte redução das vendas de praticamente todas as empresas da região. Projetos como a implantação de uma nova Unidade de Aprendizagem na região e que viria a qualificar a capacitação de mão-de-obra com recursos do Governo Federal, foram suspensos.

Para superar esse período de crise e recessão o comitê gestor focou na prospecção de mercado que, com o apoio de outras instituições da região, buscaram qualificar as pesquisas de mercado, visando prospectar clientes potenciais e alavancar novos negócios. Outra estratégia adotada foi o fomento para a participação dos empresários em eventos e realização de feiras. Nesse período foram realizadas três prospecções de mercado que compreenderam o mapeamento de inúmeras regiões do País com potencial para negócios. Um dos eventos realizado pelo APL Pós-Colheita foi a organização do TECNOPÓS (Mostra Tecnológica da Indústria Pós-Colheita e Seminário Nacional de Inovação Tecnológica e Empreendedorismo do APL Pós-Colheita), uma feira tecnológica vinculada à produtos e processos de pós-colheita de grãos que mantem-se até a data desta pesquisa e é realizado bianualmente para a difusão de conhecimento, inovação, troca de tecnologia, exposições e novos negócios entre as empresas do APL, do Brasil e do exterior, tendo se consolidado como um dos mais importantes eventos do calendário do agronegócio brasileiro.

No que concerne ao comportamento dos atores, a trajetória do Arranjo Produtivo Local Pós-Colheita, segmentada nos quatro períodos estratégicos apresentados, foi aos poucos consolidando uma configuração de relações representada na Figura 3 a partir de três grupos de atores. Um primeiro grupo se refere às organizações de alta performance com atuação supra regional (A) e que possuíam uma integração com as organizações locais, mas que detinham uma variedade de laços fracos que lhes permitiram alimentar seus processos de inovação e crescimento. Estas organizações denominadas de "empresas âncoras" criaram um diversificado conjunto de laços fracos que foi determinante para os processos de inovação tecnológica e abertura de novos mercados. Estas empresas foram decisivas para que, a partir da constituição do APL, fosse organizada uma estrutura de laços fortes na região, com a inclusão de um importante conjunto de empresas industriais de abrangência local. Este movimento ocorreu no sentido da constituição de laços verticais na forma de uma rede de empresas sistemistas, no sentido de ampliar alternativas de fornecimento e criar uma dinâmica competitiva local que ajustou seus custos na aquisição de componentes.

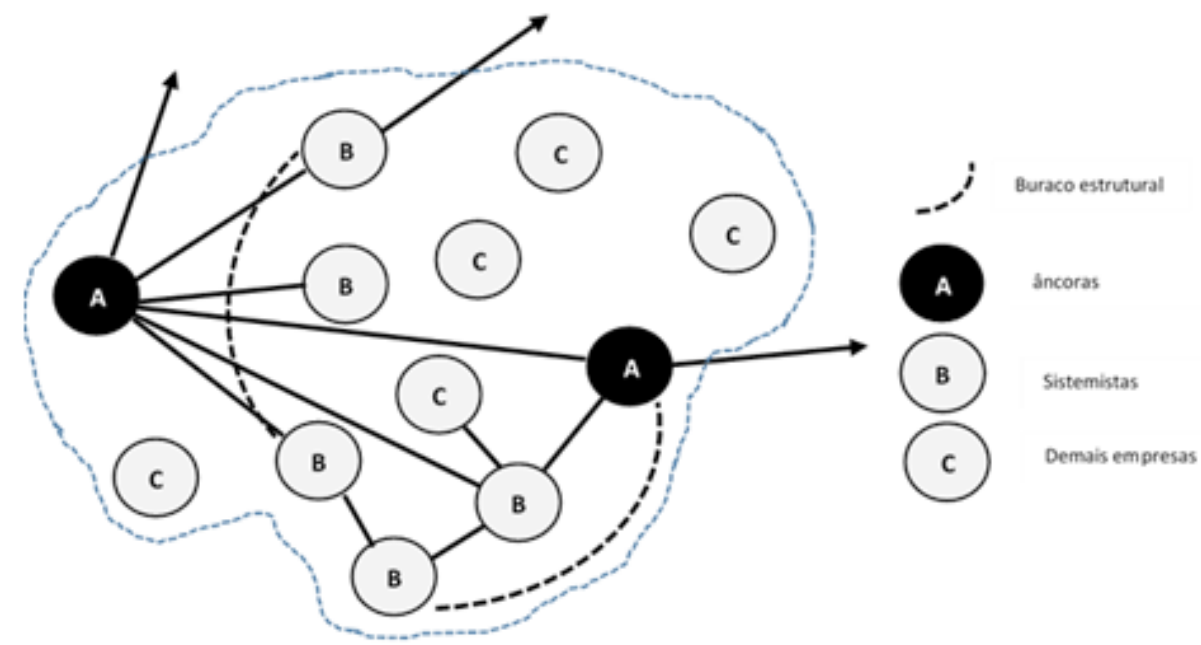

FIGURA 3 - Representação Geral das Tríades que Configuram o APL

Fonte: Sistematizado pelos autores

Organizações Rurais \& Agroindustriais, Lavras, v. 21, n. 1-3, p. 115-130, 2019 
Este movimento evidencia alguns limites na análise da tipologia de Granovetter (1973; 1983), principalmente no que concerne a dinâmica dos laços fortes. Por meio deste estudo foi possível perceber que essa análise consegue gerar evidências mais ricas se agregada às tipologias de Burt (1992) e Shipilov e Li (2012), no que concerne a formação de laços horizontais e verticais, com destaque à utilização dos "buracos estruturais" de Burt (1992). Percebeu-se que a constituição e participação da rede de laços verticais permearam os interesses, tanto das empresas âncoras como das demais indústrias locais, embora com funções e objetivos diferentes, mas não excludentes.

Constituída as dimensões de laços fortes e verticais, essas empresas âncoras foram paulatinamente se afastando do protagonismo do APL e assumindo uma posição de retaguarda em sua gestão, mas permanecendo integradas ao Comitê Gestor do APL. Este movimento, entretanto, não as retirou da dinâmica de governança que, por não possuir nenhum mecanismo autônomo de controle social, ainda era determinada pelas relações interpessoais entre 0 comitê gestor e os demais participantes.

O segundo grupo de atores é caracterizado pelas empresas sistemistas, tanto nas relações com as empresas âncoras, como também entre as demais empresas deste aglomerado industrial. Este grupo de empresas, representados pela denominação B, na Figura 3, ampliou a relação negocial principalmente pelos laços verticais e também estabeleceu relações mais densas, se não de troca de tecnologias, mas no mínimo de uma clareza maior em termos de especificações de produtos que acabam viabilizando a busca ou desenvolvimento de inovações por parte destes sistemistas. Segundo os dados da pesquisa, embora ocorra esta relação mais complexa em termos de laços verticais, ela ainda enquadra-se apenas nos denominados "laços fortes" e tangencia relações com atores que poderiam provocar maiores transformações em termos de processo produtivo e produtos.

O terceiro extrato de empresas são aquelas que não se configuram como sistemistas, apesar de eventualmente realizarem operações com outras organizações do APL. Estas empresas fazem parte do APL atuando no mesmo mercado, muitas vezes disputando os mesmos clientes e compartilhando fornecedores (C). Este é o grupo de empresas mais numeroso e que também tem participação no Comitê Gestor do arranjo. Estas empresas também integram o que neste estudo especificou-se como laços fortes, porém, na tipologia de Burt (1992), possuem preponderantemente laços horizontais.

\section{CONSIDERAÇÕES FINAIS}

$\mathrm{O}$ artigo analisou o processo de mudança na perspectiva estratégica do Arranjo Produtivo Local Póscolheita de Panambi-Condor, das estratégias coopetitivas adotadas pelo comitê gestor em um sistema de governança colaborativa. A análise permitiu identificar que a articulação dos membros do comitê gestor, a partir de um modelo colaborativo, embora ainda incipiente em termos de sistema, conduzido por meio da habilidade social de suas lideranças, permitiu que as alianças fossem construídas fortalecendo a cooperação inter organizacional que potencializou a constituição de uma densa relação de "laços fortes" que resultou, no mínimo, em uma elevada legitimidade do APL junto a seus diversos interlocutores.

Pôde-se perceber que as empresas, ao pertencer a um APL já legitimado, em termos de imagem e interações sociais internas mais robustas (laços fortes), têm aumentado às possibilidades para que qualquer um de seus atores constitua "laços fracos" de qualidade. Em termos das diversas tríades que lhe dão sustentação (BURT, 1992; SHIPILOV; LI, 2012), identifica-se uma dimensão que não é evidenciada por Granovetter (1983), principalmente na dinâmica da passagem de laços horizontais para laços verticais e o modo como esse movimento se reflete na dinâmica de governança do sistema. Observou-se que uma aparente posição de subserviência que poderia decorrer de tríades com buracos estruturais envolvendo as empresas âncoras, também foi utilizada no modo como as demais empresas tem se utilizado a posição para acessar novas possibilidades de produção e mercado.

Isto acaba se justificando pelos mesmos fatores que fizeram empresas a ingressar no projeto, ou seja, pertencer ou relacionar-se com um projeto/sistema legitimado e com reputação elevada. Mesmo que o APL ainda não consiga efetivar grande parte de seus objetivos, este fato talvez seja um dos grandes potenciais que possam ser aprofundados no futuro e que pode caracterizar seu novo período estratégico: pulverizar a constituição de "laços fracos" por parte de seus componentes. Em termos de fragilidade, ficou evidente na análise realizada a incipiência dos instrumentos de governança, principalmente aqueles de controle social mais ampliado, que possam ter uma dinâmica autônoma, independente do olhar do Comitê Gestor. Dado a este fato, a busca da convergência recaiu, em muito, na habilidade do Comitê Gestor do APL em produzir este alinhamento de modo quase que artesanal, gerenciando cada situação individualmente e trabalhando para manter uma ideologia de agregação e cooperação. 
Finalmente, um aspecto fundamental é que, a confiança entre os atores ainda se constitui no grande desafio para este tipo de empreendimento. No caso analisado, apesar de haver uma aparente confiança entre os diversos componentes, subgrupos acabaram se constituindo informalmente em função de interesse que, se por um lado, agregava expectativas comuns, por outro lado, constituía um campo fértil para a emergência de conflitos, explícitos ou velados. A estrutura de governança presente nesta experiência não foi capaz de interferir de modo consistente neste movimento, conseguiu apenas garantir que não houvesse rupturas significativas. As relações de confiança estabelecidas foram majoritariamente entre pessoas que representavam as organizações e não entre as organizações, o que converge com o identificado por Adami e Verschoore (2014). Também não foi observada uma sólida interdependência sistêmica entre as diversas organizações, estando mais presente as relações funcionais (horizontais ou verticais). Pode-se levantar, como hipótese, que a fragilidade destas interdependências acaba retirando muito do vigor que poderia assumir o arranjo produtivo se houvesse uma maior densidade nas relações. Por outro lado, provavelmente seria ingênua uma expectativa de cooperação plena dos diversos atores visto que, pela fragilidade do caráter orgânico do APL, muitas empresas disputam os mesmos mercados e buscam as mesmas fontes de inovação para diferenciarem-se. Vale um destaque final na análise para a dinâmica que se estabeleceu nas relações envolvendo os buracos estruturais, com algumas empresas utilizando-os para influenciar elementos das tríades e outras buscando usufruir desta posição para como estratégia mercadológica e de inovação, tema que exige um maior aprofundamento.

\section{REFERÊNCIAS}

ADAMI, V. S., VERSCHOORE, J. R. Confiança em relacionamentos interorganizacionais triádicos. Revista Alcance, Biguaçu, v. 21, n. 2, p. 350-368, 2014.

AGRANOFF, R. Managing collaborative performance: changing the Boundaries of the State?. Public Performance \& Management Review, Londres, v. 29, n. 1, p. 18-45, 2005.

ALVES, J. N.; PEREIRA, B. A. D.; ANDRADE, T.; REIS, E. D. Confiança, aprendizagem e conhecimento nos relacionamentos interorganizacionais: diagnóstico e análise dos avanços sobre o tema. REAd. Revista Eletrônica de Administração, Porto Alegre, v. 19, n. 3, p. $709-737,2013$.
ANSELL, C.; GASH, A. Collaborative governance in theory and practice. Journal of Public Administration Research and Theory, Oxford, v. 18, n. 4, p. 543-571, 2008.

ASTLEY, W. G. Toward an appreciation of collective strategy. The Academy of Management Review, Nova York, v. 9, n. 3, p. 526-535, 1984.

ASTLEY, W. G.; FOMBRUN, C. J. Collective strategy: social ecology of organizational environments. Academy of Management Review, Nova York, v. 8, n. 4, p. 576$587,1983$.

BARDACH, E. Developmental dynamics: interagency collaboration as an emergent phenomenon. Journal of Public Administration Research and Theory, Oxford, v. 11, n. 2, p. 149-164, 2001.

BARNEY, J. B.; HESTERLY, W. Economia das organizações: entendendo a relação entre organizações e análise econômica. In: CLEGG, S. R.; HARDY, C.; NORD. W. R. (Orgs.). Handbook de Estudos Organizacionais, São Paulo: Atlas, v. 3, 2012.

BASSO, D.; TRENNEPOHL, D. (Org). Planejamento estratégico de arranjos produtivos locais: plano de desenvolvimento do APL metalmecânico pós-colheita Panambi e Condor 2012-2022. Ijuí: Unijuí, 2012.

BENGTSSON, M.; KOCK, S. "Coopetition” in Business Networks - to Cooperate and compete simultaneously. Industrial Marketing Management, Frederiksberg, v. 29, n. 5, p. 411-426, 2000.

BERARDO, R.; LUBELL, R. Understanding What Shapes a Polycentric Governance System. Public Administration Review, Londres, v. 76, n.5, p. 738-751, 2016.

BERARDO, R. Bridging and Bonding Capital in TwoMode Collaboration Networks. Policy Studies Journal. Washington, D. C., v. 42, n. 2, p. 197-225, 2014.

BODIN, O.; NOHRSTEDT, D. Formation and performance of collaborative disaster management networks: Evidence from a Swedish wildfire response. Global Environmental Change, Amsterdam, v. 41, p. 183-194, 2016. 
BODIN, O. Collaborative environmental governance: achieving collective action in socialecological systems. Science, Nova York, v. 357, n. 6352, p. 659-668, 2017.

BOURDIEU, P. Outline of a theory of practice. Cambridge: Cambridge University Press, 1977.

BOURDIEU, P. Razões práticas: sobre a teoria da ação. Campinas: Papirus, 1996.

BRETTEL, M. CLEVEN, N. Innovation culture, collaboration with external partners and NPD performance. Creativity and Innovation Management, Enschede, v. 20, n. 4, p. 253-272, 2011.

BURT, R. S. Structural Holes: the social structure of competition. Cambridge: Harvard University Press, 1992.

BURT, R. S.; KILDUFF, M.; TASSELLI, S. Social Network Analysis: Foundations and Frontiers on Advantage. Annual Review of Psychology, New Haven, v. 64, n. 1, p. 527-547, 2013.

CASSiOlato, J. E.; SZAPIRO, M. Arranjos e sistemas produtivos e inovativo locais no Brasil. Políticas para promoção de sistemas produtivos locais de MPME: set. 2002. Disponível em: http://www. ie.UFRJ.br/redesist/NTF2/NT\%20CassioMarina.PDF. Acesso em: 20 out. 2018.

COASE, R. H. The Nature of the Firm. The London School of Economics and Political Science, Londres, v. 4, n. 16, p. 386-405, 1937.

COSTA, A. P. P.; WOOD Jr. Fraudes Corporativas. Revista de Administração de Empresas, São Paulo, v. 52, n. 4, p. 464-472, 2012.

DAY, M.; FAWCETT, S. E.; FAWCETT, A. M., MAGNAN, G. M. Trust and relational embeddedness: exploring a paradox of trust pattern development in key supplier relationships. Industrial Marketing Management, Frederiksberg, v. 42, n. 2, p. 152-165, 2013.

DiMAGGiO, P. J., POWELL, W. W. The iron cage revisited: institutional isomorphism and collective rationality in organizational field. American Sociological Review, Chicago, v. 48, n. 2, p. 147-160, 1983.
EMERSON, K.; NABATCHI, T.; BALOGH, S. An integrative framework for collaborative governance. Journal of Public Administration Research and Theory, Oxford, v. 22, n. 1, p. 1-29, 2012.

FLIGSTEIN, N. Habilidade social e a teoria dos campos. Revista de Administração Eletrônica, São Paulo, v. 47, n. 2, p. 61-80, 2007.

GERLAK, A. K.; HEIKKILA, T. Collaboration and institutional endurance in US water policy. Political Science \& Politics, Washington, D. C., v. 40, n. 1, p. 55-60, 2007.

GIDDENS, A. A constituição da sociedade. São Paulo: Martins Fontes, 1984.

GRANOVETTER, M. S. The strength of weak ties. American Journal of Sociology, Chicago, v. 78, n. 6, p. 1360-1380, 1973.

GRANOVETTER, M. S. The strength of weak ties: a network theory revisited. In: Sociological Theory. San Francisco: Ed. Randall Collins, 1983.

GUERRA, R. M. A.; TONDOLO, V. A. G.; CAMARGO, M. E. O que (ainda) podemos aprender sobre capacidades dinâmicas. Revista Ibero-Americana de Estratégia RIAE, São Paulo, v. 15, n. 1, 2016.

HEIKKILA, T.; GERLAK, A. K. Building a conceptual approach to collective learning: lessons for public policy scholars. Policy Studies Journal, Washington, D. C, v. 41, n. 3, p. 484-512, 2013.

HREBINIAK, L. G.; JOYCE, W. F. Organization adaptation: strategic choice and environmental determinism. Administrative Science Quarterly, Nova York, v. 30, p. 336-349, 1985.

HUMPHREY, J.; SCHMITZ, H. Trust and Economic Development (IDS Discussion Paper). Londres: Institute of Development Studies, 1996.

INSTITUTO DE PESQUISA ECONÔMICAAPLICADA. Texto para discussão: A evolução do crédito no Brasil entre 2003 e 2010. Brasília, 2014.

JENSEN, M.; MECKLING, W. Theory of the firm: managerial behavior, agency costs and ownership structure. Journal of Financial Economics, Nova York, v. 3, n. 4, p. 305-360, 1976. 
KÜHL, M.R. Interdependência entre a colaboração para a inovação e o desempenho sustentável na indústria brasileira de eletroeletrônicos. 2012. 257 p. Tese (Doutorado em Estratégia e Organizações) Universidade Federal do Paraná, Paraná, 2012.

LUBELL, M.; MEWHIRTER, J.M.; BERARDO, R.; SHALZ, J.T. Transaction costo and the perceived effectiveness of complex institutional systems. Public Administration Review, Washington, D. C., v.77, n.5, p.668-680, 2017.

MINTZBERG, H. The Structuring of Organizations: a synthesis of the research. New Jersey: Pearson, 1979.

NALEBUFF, B. J.; BRANDENBURGER, A. M. Coopetition: competitive and cooperative business strategies for the digital economy. Strategy \& Leadership, Nova York, v. 25, n. 6, p. 28-33, 1997.

O’DWYER, G.; MATTOS, R. A. Teoria da estruturação de Giddens e os estudos de práticas avaliativas. Physis Revista de Saúde Coletiva, Rio de Janeiro, v. 20, n. 2, p. 609-623, 2010.

PETTIGREW, A. M.; FERLIE, E.; McKEE, L. Shaping Strategic Change. London: Sage publications, 1992.

PACHECO, J. R.; ARRUDA, J. R. Análise do contexto em que está situado o APL metalmecânico pós colheita - Panambi e Condor. In: BASSO, D.; TRENNEPOHL, D. (Orgs.) Planejamento estratégico de arranjos produtivos locais: plano de desenvolvimento do APL metalmecânico pós-colheita - Panambi e Condor 20122022. Ijuí: Unijuí, 2012. p. 33-44.

QUANDT, C. O. Redes de cooperação e inovação localizada: estudo de caso de um arranjo produtivo local. Revista de Administração e Inovação, São Paulo, v. 9, n. 1, p. 141-166, 2012.

RICHARDSON, R. J. Pesquisa social: métodos e técnicas. 4. ed. São Paulo: Atlas, 2017.

RING, P. S.; VAN DE VEN, A. H. Developmental processes of cooperative interorganizational relationships. Academy of Management Review, Nova York, v. 19, n. 1, p. 90-118, 1994.
SHIPILOV, A. V.; LI, S. X. The missing link: the effect of customers on the formation of relationships among producers in the multiplex triads. Paper forthcoming in Organization Science Special issue on the Genesis of Networks, 2012.

SILVEIRA, A. Di M. Governança Corporativa No Brasil e No Mundo. Rio de Janeiro: Elsevier, 2015.

SUZIGAN, W.; GARCIA, R.; FURTADO, J. Estruturas de governança em arranjos ou sistemas locais de produção. Gestão e Produção, São Carlos, v. 14, n. 2, p. 425-439, 2007.

TENÓRIO, F. G (Org.). In: CANÇADO, A. C.; SAUSEN, J. O; VILLELA, L. E. Gestão social e Gestão estratégica - experiências em desenvolvimento territorial. Rio de Janeiro: FGV, 2013.

VILLELA, L. E.; PINTO, M. C. S. Governança e gestão social em redes empresariais: análise de três arranjos produtivos locais (APLs) de confecções no estado do Rio de Janeiro. Revista de Administração Pública, Rio de Janeiro, v. 43, n. 5, p. 1067-1089, 2009.

WILLIAMSON, O. E. The Economic Institutions of Capitalism. New York: Free Press, 1996.

WOITCHUNAS, L. F.; SAUSEN, J. O.; FROEMMING, L. M. S.; SIEDEMBERG, D. R. Uma Análise das Vantangens Competitivas de um Território a partir do Modelo Diamante de Porter: o caso do APL Metalmecânico Pós Colheita Panambi/Condor no RGS. Revista Brasileira de Gestão e Desenvolvimento Regional, Taubaté, v.14, n. 2, p. 300-324, 2018.

WOOLTHUIS, R.K; NOOTEBOOM, B.; DE JONG, G.; FAEMS, D. The roles of Third Parties in Strategic Alliance Governance. In: DAS, T. K. (Ed.). Interpartner Dynamics in Strategic Alliances, USA: Information Age Publishing Inc., 2013.

ZOLTAN, R. Interfirms collaboration - the basis for interorganizational innovation. Annals of Dunarea de Jos. Universtty of Galati. Fasc.1. 2010.

Organizações Rurais \& Agroindustriais, Lavras, v. 21, n. 1-3, p. 115-130, 2019 